\title{
PENGARUH MEDIA TANAM AKUAPONIK YANG BERBEDA TERHADAP PENURUNAN NITRAT DAN POSPAT PADA PEMELIHARAAN IKAN MAS (Cyprinus carpio)
}

\section{THE EFFECT OF VARIOUS CULTIVATING MEDIA OF AQUAPONIC ON DECREASING OF NITRATE AND PHOSPHATE IN COMMON CARP (Cyprinus carpio) CULTURE}

\author{
Andika Gumilang Kushayadi ${ }^{1 *}$, Saptono Waspodo ${ }^{1)}$, Nanda Diniarti ${ }^{1)}$ \\ ${ }^{1)}$ Program Studi Budidaya Perairan, Universitas Mataram \\ Jl.Pendidikan No, 37 Mataram NTB
}

\begin{abstract}
Abstrak
Penelitian ini bertujuan untuk mengetahui perbedaan media tanam pada akuaponik terhadap pernurunan kadar nitrat dan posfat pada kolam pemeliharaan ikan mas. Penelitian di rancang menggunakan Rancangan Acak Lengkap (RAL). Perlakuan terdiri dari 4 perlakuan dengan 3 ulangan.. Perlakuan terdiri atas satu kontrol (tanpa akuaponik) dan tiga aquaponik yang menggunakan media tanam yang berbeda.Media tanam yang digunakan sebagai bahan uji adalah batu apung, akar pakis, dan serabut kelapa. Batu apung memberikan pengaruh yang signifikan terhadap penurunan nitrat dan pospat. Berdasarkan penelitian ini batu apung menurunkan nnitrat dan pospat sejumlah $65,55 \%$ dan $94,06 \%$. Penggunaan batu apung memberikan sintasan $69,3 \%$ dengan laju pertumbuhan spesifik sebesar $2,3 \%$ per hari.
\end{abstract}

Kata Kunci : akar pakis, akuaponik, batu apung, ikan mas, pospat, nitrat, serabut kelapa

\begin{abstract}
This reasearch aimed to know the effect of various aquaponic media on decreasing of nitrate and phosphate level in common carp culture. This research was designed with Completely Randomize Design with four treatment and three replications. Treatments consist of one control (without aquaponic), aquaponic with pumice media, aquaponic with fern roots media, and aquaponic with coconut fiber media. Pumice media gave significant value in decreasing nitrate and phospate level. Nitrate and phospate level decreased of $65,55 \%$ and $94,06 \%$, respectively. Aquaponic with pumice media result $69,3 \%$ of survival rate and $2,3 \%$ of spesific growth rate per day.
\end{abstract}

Keywords : aquaponic, coconut fiber, common carp, fern roots, nitrate, phospate, pumice.

\section{Pendahuluan}

Dalam mengatasi jumlah lahan yang sempit, peternak ikan menggunakan sistem budidaya intensif. Penggunaan sistem intensif membuat produksi ikan menjadi lebih tinggi dikarenakan pada lahan yang sempit padat penebaran yang dilakukan tinggi. Padat penebaran yang tinggi menyebabkan jumlah bahan organik terlarut di kolam menjadi lebih tinggi dalam waktu yang singkat. Akihino (2015) menyatakan dalam $1 \mathrm{~kg}$ proses produksi ikan air tawar saja akan menghasilkan limbah produksi yang terdiri dari 90,4 g Nitrogen, dan 10,5 g Posfor, padahal berdasarkan Peraturan Menteri *email korespondensi: kushayadi.Sci@gmail.com
Lingkungan Hidup Republik Indonesia No 3 tahun 2010 tentang baku mutu air bahwa kandungan maksimum nitrogen adalah sebesar $20 \mathrm{mg} / \mathrm{l}$ dan BOD (Biological Oxygen Demand) sebesar $50 \mathrm{mg} / \mathrm{l}$, sehingga perlu adanya sebuah sistem terpadu pengolahan air limbah budidaya ikan sebelum dilepas ke perairan umum.

Salah satu solusi yang mengatasi berlebihnya jumlah nitrat dan pospat di air budidaya ikan adalah dengan melakukan pembuangan nitrat dan pospat menggunakan biota yang dapat memanfaatkan nitrat dan posfat, salah satunya tanaman. Budidaya terintegrasi antara ikan dan tanaman lebih dikenal dengan nama akuaponik. 
Akuaponik merupakan teknologi budidaya tanaman hidroponik (tanpa media tanah) dengan budidaya perairan (aquaculture) dalam suatu wadah yang terintegrasi (Kyaw dan Ng, 2017).Tujuan dari aquaponik adalah untuk mendapatkan hasil pertanian dan perikanan diwaktu yang hampir bersamaan, dalam rangka menghadapi keterbatasan lahan dan air (Rifa'i dan Ika., 2012). Hasil sekresi ikan adalah amonia. Sistem pemeliharaan ikan dengan akuaponik akan memompa amonia di kolam pemeliharaan ikan menuju ke media tanam akuaponik, di media tanam amonia akan dirombak oleh bakteri pengurai nitrogen menjadi nitrat dan dimanfaatkan oleh tanaman lalu di lepas kembali ke wadah pemeliharaan ikan (Cohen dkk. 2018). Penelitian yang dilakuan Dauhan dkk., (2014) menyatakan sistem akuaponik dengan jumlah rumpun tanaman kangkung dapat menyerap nitrat sebanyak 58,57 mg/l. Sementara penggunaan tanaman air hidrila dapat menekan jumlah posfat pada kisaran $0.287 \mathrm{mg} / \mathrm{l}$ (Dwiyanti dan Gunadi, 2006).

Media tanam akuaponik secara umum seperti serabut kelapa, akar pakis, dan batu apung memberikan pengaruh sebagai filter air di dalam kolam terutama terhadap nitrat dan pospat sisa perombakan pakan ikan. Ditambah dengan penggunaan tanaman maka akan membentuk sistem biofilter (Fang dkk. 2017). Air yang terolah dengan baik akan menunjang pertumbuhan ikan dengan baik sehingga produksi ikan dapat ditingkatkan. Kajian tentang media tanam yang ideal tentang akuaponik belum banyak diteliti. Data efektifitas media tanam yang tepat sangat berguna untuk memilih media tanam dengan simbiosis mutualisme yang bagus terhadap kualitas air.

\section{Metode Penelitian}

Penelitian ini meggunakan metode eksperimental dengan Rancangan Acak Lengkap (RAL) dimana pengaruh dari luar dianggap homogen. Penelitian menguji konsentrasi amonium dan posfat dengan menggunakan media tanam akuaponik yang berbeda dimanadilakukan 4 perlakuan. P1: Tanpa penggunaan media akuaponik (Kontrol); P2: Serabut Kelapa; P3: Batu Apung; P4: Akar Pakis.Masing masing ulangan akan diulang sebanyak 3 kali sehingga didapatkan 12 unit percobaan.
Penelitian dilakukan dengan membandingkan efektifitas dari media tanam akuaponik yang berbeda terhadap konsentrasi nitrat dan posfat pada air pemeliharaan ikan mas. Data yang diambil adalah data kualitas air dan pertumbuhan ikan serta tanaman. Untuk data kualitas air, sampel diambil menggunakan botol sampel sebanyak $50 \mathrm{ml}$ dengan interval pengambilan data 5 hari sekali. Data yang dikumpulkan selama penelitian dibagi menjadi dua tipe yakni data primer dan data sekunder, dimana data primer dibagi lagi menjadi dua parameter yakni parameter utama dan pendukung. Parameter utama meliputi konsentarsi nitrat dan posfat. Konsentrasi nitrat dan pospat yang diukur dengan menggunakan spektrofotometer UV-IS pada inlet dan outlet. Penyerapan nitrat dan pospat (c) diukur dengan menggukur selisih di Inlet (a) dan outlet (b) dengan rumus $\mathrm{a}-\mathrm{b}=\mathrm{c}$. Parameter pendukung meliputi, DO, $\mathrm{pH}$, Suhu, serta sinatsan.

\section{Hasil}

\section{Penurunan Nitrat}

Berdasarkan analisa sidik ragam, penurunan nitrat terbesar terjadi pada media tanam batu apung. Batu apung menurunkan nitrat sebesar 69,55 . Perlakuan batu apung berbeda nyata terhadap keseluruhan perlakuan. Secara berturut - turut dengan serabut kelapa, akar pakis dan kontrol. Tidak ada penurunan nitrat pada kontrol. Data disajikan pada Gambar 1

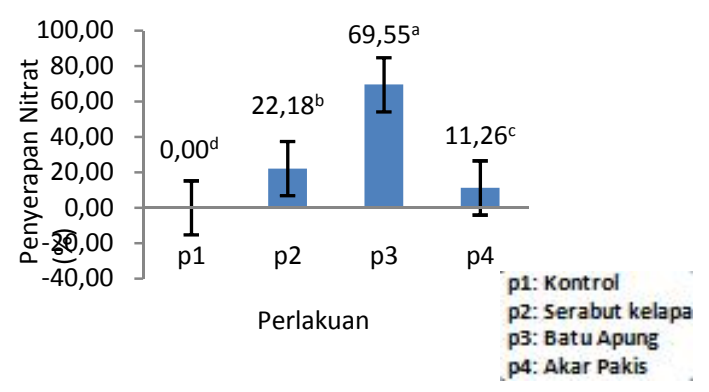

\section{Gambar 1. Penurunan nitrat}

\section{Penurunan Pospat}

Dari hasil analisis sidik ragam (Gambar 2) P3 menunjukan nilai terbaik dimana $P 3$ berbeda nyata antar perlakuan kecuali P2 dan P4 yang tidak menunjukan adanya beda nyata. Penurunan pospat pada batu apung terhitung sebesar 94,06 \% serabut kelapa 41,31\% dan 
akar pakis 34,21 \%.. Tidak ada penurunan pospat pada perlakuan kontrol.

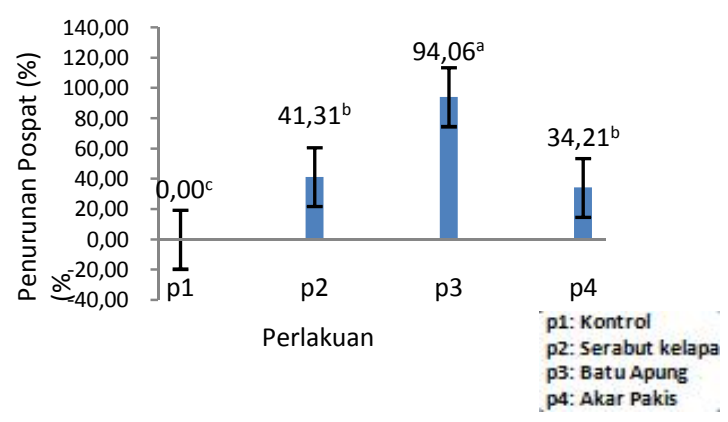

Gambar 2. Penurunan pospat

\section{Kualitas Air (DO, pH, Suhu)}

Kualitas air berupa DO dan $\mathrm{pH}$ pemeliharaan ikan mas dengan sistem akuaponik aliran atas menunjukan hasil yang baik pada penggunaan batu apung (P3) lalu diikuti oleh P2 (Serabut kelapa), P4 (Akar Pakis), kemudian P1 yang merupakan kontrol. Nilai DO berturut-turut adalah 5,$1 ; 4,41 ; 4,18$; dan 3,77 . Untuk $\mathrm{pH}$ berturut-turut sebagai berikut 7,07; 6,94; 6.92; dan 5,602. Untuksuhu tidak menunjukan adanya perubahan, kisaran suhu antar perakuan berada pada kisaran 28 29 oC. Grafik dapat dilihat pada Gambar 3.

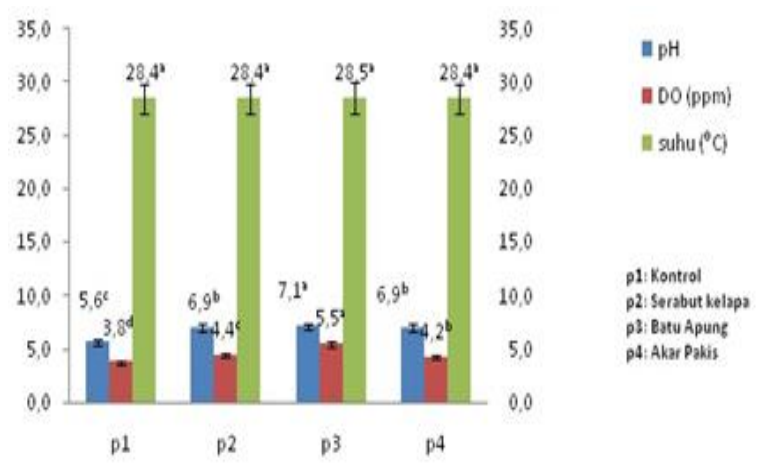

Gambar 3. Kualitas air

Hasil analisis sidik ragam untuk DO menunjukan P3 dengan media tanam batu apung memberikan pengaruh yang berbeda nyata antar perlakuan. Begitu pula dengan $\mathrm{pH}$, P3 dengan media tanam batu apung memberikan pengaruh yang berbeda nyata antar perlakuan terkecuali P2 yang menggunakan media tanam serabut kelapa dengan P4 yang menggunakan media tanam akar pakis yang tidak menunjukan beda nyata. Suhu bedasarkan analisis sidik ragam tidak menunjukan adanya beda nyata antar perlakuan.

\section{Survival Rate (Kelulusan Hidup)}

Perlakuan 3 dengan penambahan media tanam batu apung memberikan hasil yang paling tinggi dalam indeks survival rate atau derajat kelangsungan hidup ikan mas yakni sebesar $69.33 \%$, lalu diikkuti oleh P2 dengan penggunaan serabut kelapa sebesar $49 \%$, lalu perlakuan P4 dengan penggunaan media tanam akar pakis, dan P1 yaitu kontrol. Dari hasil analisis sidik ragam didapatkan P3 berbeda nyata antar perlakuan terkecuali P4 dan P1 yang tidak menunjukan adanya beda nyata. Grafik dapat dilihat pada Gambar 4.

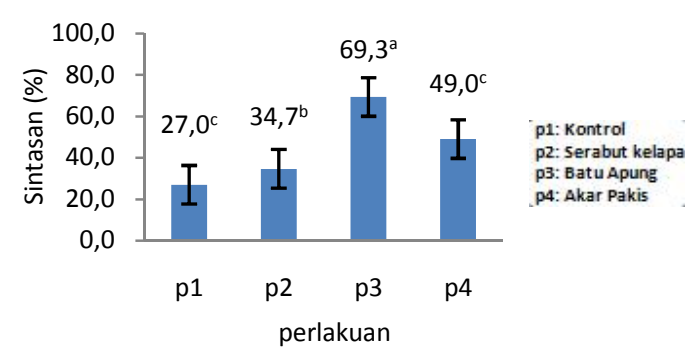

Gambar 4. Sintasan

\section{Laju Pertumbuhan Ikan}

Pertumbuhan ikan tertinggi terlihat pada pemberian media tanam berupa batu apung (P3) sebesar $2.425 \%$. Artinya laju pertambahan berat sebesar $2,425 \%$ selama pemeliharaan. Lalu diikuti dengan P2 (Media Tanam Serabut Kelapa) sebesar $1.439 \%$ lalu P4 Media Tanam Akar Pakis $1.119 \%$, dan kontrol $0.798 \%$. dilihat dari hasil analisis sidik ragam ditemukan adanya beda nyata dimana P3 berbeda nyata antar perlakuan. Grafik bisa dilihat di Gambar 5 .

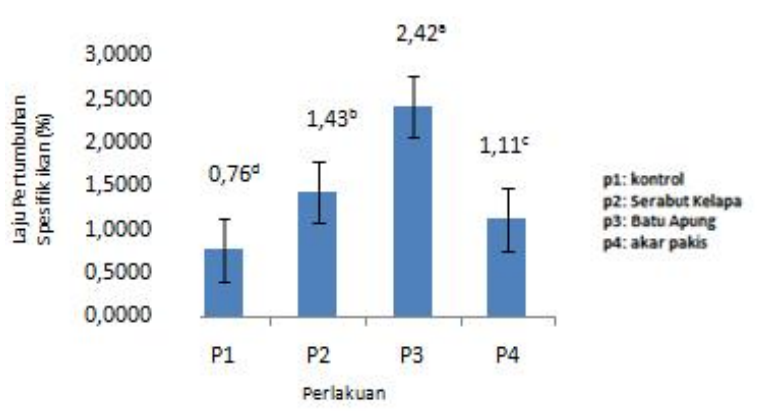

Gambar 5. Laju Pertumbuhan Ikan 


\section{Laju Pertumbuhan Sawi}

Perlakuan 3 dengan penamahan media tanam batu apung memberikan hasil yang paling tinggi dalam laju pertumbuhan sawi yakni sebesar 1,607 \%, lalu diikkuti oleh P2 dengan penggunaan serabut kelapa sebesar $0.923 \%$, lalu perlakuan P4 dengan penggunaan media tanam akar pakis sebesar 0.4418 , dan P1 yaitu kontrol. Dari hasil analisis sidik ragam didapatkan $\mathrm{P} 3$ berbeda nyata antar perlakuan terkecuali P4 dan P2 yang tidak menunjukan adanya beda nyata. Grafik dapat dilihat pada Gambar 6

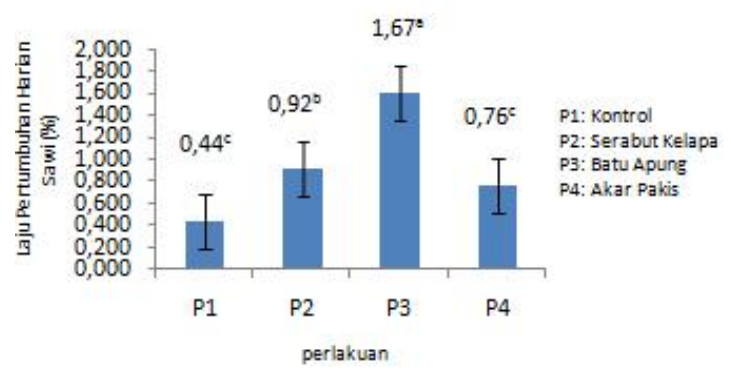

Gambar 6. Laju pertumbuhan sawi

\section{Pembahasan}

Media tanam berupa batu apung memberikan pengaruh yang paling significant terhadap penurunan nitrate di wadah pemeliharaan. Batu apung menurunkan nitrat sebesar 69,55\%, hal ini diduga karena pada batu apung bakteri pengurai Nitrogen seperti nitrozomonas dan nitrozobacter banyak hidup, Cohendkk. (2018) menyatakan bahwa batu apung tersusun atas unsur $\mathrm{SiO} 2, \mathrm{AlO} 3, \mathrm{CaO}$, $\mathrm{MgO}, \mathrm{NaO}$ dan I dimana keberadaan unsur oksida silika dan kalsium merupakan tempat optimum keberadaan nitrozobacter maupun nitrozomonas, hal ini sejalan dengan pernyataan Somervile dkk.(2014) yang menyebutkan bahwa bakteri pengurai Nitrogen hidup pada lokasi dengan banyak mineral Kalsium dan silikat. Penelitian yang dilakukan Wongkiew dkk. (2017) menyatakan bahwa dalam batu apung terdapat silika dan kalsium dengan rasio $3: 1$, hal ini memungkinkan untuk tumbuhnya bakteri pengurai nitrogen yang membutuhkan syarat hidup pada kisaran 20 $78 \%$ kandungan silika dan kalsium. Selain itu Cohen (2010) menjelaskan lebih lanjut bahwa batu apung memiliki besar pori rata-rata sebesar 0,45 mikron sehingga dapat menjerap amonium yang memiliki besar molekul sebesar 0,98 mikron. Amonium yang terserap kemudian diolah oleh bakteri pengurai $\mathrm{N}$ yang ada di batu apung menjadi nitrat lalu dimanfaatkan oleh tanaman sehingga air buangan menjadi lebih bersih.

Kandungan silika juga dapat kita temukan di serabut kelapa dengan jumlah yang sangat terbatas yakni 1,28 \% (Yang dkk., 2018). Kandungan yang kecil itu tidak memungkinkan untuk tumbuh bakteri pengurai Nitrogen. Namun serabut kelapa memiliki kerapatan serat yang tinggi, Carvalho dkk. (2018) menyatakan bahwa serabut kelapa memiliki kerapatan jenis serat sebesar 0,56 mikron, hal ini sudah cukup untuk menahan amonium yang memiliki besar molekul 0,98 mikron. Meskipun demikian, molekul amonium pada media filter serabut kelapa hanya tertahan dan tidak terurai, karena tidak memungkinkan untuk tumbuhnya bakteri pengurai N.Amonium tidak dapat dimanfaatkan oleh tanaman secara langsung, karena tanaman hanya bisa memanfaatkan amonium yang sudah terurai menjadi nitrat oleh bakteri pengurai $\mathrm{N}$.

Pada akar pakis tidak dijumpai sedikitpun keberadaan silika dan kalsium. Lee dkk. (2018) dalam penelitiannya menjelaskan bahwa akar pakis merupakan media yang kurang ideal dalam akuaponik, hal ini didasari pada kerapatan serat sebesar 0,85 mikron serta tidak ditemukannya kandungan silika ataupun kalsium yang merupakan syarat mutlak untuk hidupnya bakteri pengurai Nirogen. Berkurangnya konsentrasi amonium pada media tanam akar pakis lebih mengarah kepada molekul amonium yang tertahan di serat akar pakis dan tidak bisa dimanfaatkan oleh sawi (Pranawa, 2013).

- Dalam penurunan pospat Lindsay (2009) menyatakan bahwa unsur silika dalam batu apung berbentuk oksida silika $\mathrm{SiO} 2$. Apabila terkena air, maka unsur $\mathrm{O}$ akan terlepas dengan unsur Si karena mengalami deoksidasi. Kekosongan ion O pada Si akan menyebabkan Si menarik ion sekitar sehingga mencapai titik setimbang, pada saat ini lah ion $\mathrm{O}$ pada posfat (PO4) tertarik dan dipecah oleh silikat tunggal untuk membentuk $\mathrm{SiO} 2$ dan membuang 2 ion $\mathrm{O}$ lainnya dalam bentuk oksigen bebas O2. Senyawa Pospat tunggal (P) ini kemudian diserap oleh tanaman guna pembentukan dinding sel. Adapun reaksi kimia pospat dan batu apung dapat dilihat oleh 
persamaan berikut iniSiO2 $+\mathrm{H} 20-\mathrm{Si}+4 \mathrm{O}+$ $\mathrm{H}$ (Deoksidasi awal); $\mathrm{Si}+4 \mathrm{O}+\mathrm{H}-\mathrm{Si}+$ $(2 \mathrm{H} 2 \mathrm{O}+2 \mathrm{O})-$ Oksigen Terlarut ; $\mathrm{Si}+\mathrm{PO} 4-$ $\mathrm{SiO} 2+2 \mathrm{O}+\mathrm{P}$ (Penyerapan $\mathrm{P}$ oleh tanaman $)$

Penggunaan media tanam batu apung membuat $\mathrm{pH}$ media tanam berada pada kisaran normal diakibatkan dari penyerapan amonium yang terjadi di media tanam batu apung.Amonium merupakan substansi asam sehingga apabila berada pada lingkungan budidaya secara berlebihan akan menyebabkan pH menjadi turun (Sutrisno,2007). Pada media tanam batu apung bakteri pengurai $\mathrm{N}$ seperti nitrozomonas dan nitrozobacter banyak hidup (Somervile dkk., 2014).

Bakteri pengurai $\mathrm{N}$ hidup pada lokasi dengan banyak mineral calcium dan silikat meskipun pada beberapa hutan hujan tropis dapat ditemukan juga di tanah dengan sulfur. Hal ini diperkuat dengan pernyataan Cohen (2010) bahwa batu apung tersusun atas unsur $\mathrm{SiO} 2, \mathrm{AlO} 3, \mathrm{CaO}, \mathrm{MgO}, \mathrm{NaO}$ dan I. Pujiastuti (2014) menyatakan batuan berbahan silikat seperti batu apung dapat menstabilkan $\mathrm{pH}$. PO4 merupakan substansi basa sementara silikat sangat aktif melakukan pemecahan unsur P sehingga unsur pospat dapat dipecah. Pemecahan unsur PO4 menjadi $\mathrm{P}+40$ menjadikan suasanan larutan menjadi netral (Lindsay, 2014).

Nilai survival rate akuaponik dengan media tanam batu apung lebih tinggi dikarenakan pada lingkungan dengan rendah amonium dan posfat memiliki nilai kadar oksigen terlarut yang tinggi. Namun dengan nilai survival rate sebesar $69,3 \%$, masih lebih rendah dibandingkan rata-rata survival rate ikan mas yakni berkisar pada 80- $85 \%$ (Akihino, 2015). Pada kondisi lingkungan yang kurang memadai metabolisme ikan akan meningkat sebagai dampak dari kegiatan adaptasi yang dilakukan ikan. Serangkaian kegiatan metabolisme ini memerlukan O2 yang tinggi. Selain metabolisme ikan, pengurairan amonium menjadi nitrat di air juga memerlukan banyak oksigen sebagai pengoksidasi (Sutrisno, 2007).

Akuaponik dengan media tanam batu apung memberikan kondisi pemeliharaan yang rendah amonium dan posfat. Lee dkk. (2018) menyatakan apabila pada kolom air kandungan amonium tinggi maka akan menghambat pengikatan oksigen oleh hemoglobin darah. Kondisi demikian akan menyebabkan ikan kekurangan oksigen pada beberapa organ atau yang lebih dikenal dengan Hypoxia. Keberadaan posfat yang tinggi juga akan menyebabkan penumpukan alga pada air pemeliharaan ikan sehingga akan mengganggu penetrasi cahaya yang masuk dan fotosintesis di air berkurang.

Pospat merupakan subtansi pembentukan dinding tanaman sehingga membuat pertumbuhan alga menjadi lebih cepat. Pada malam hari alga akan memanfaatkan lebih banyak $\mathrm{O}_{2}$ sehingga $\mathrm{DO}$ akan menurun drastis dalam semalam dan berujung pada kematian mendadak ikan di pagi hari. Hal demikian ditemui pada perlakuan 1 yaitu kontrol (Tanpa akuaponik) dimana ikan banyak mati.

Yang dkk (2018) yang menyatakan bahwa pada media tanam berupa batu apung merupakan media tanam yang ideal untuk pertumbuhan bakteri pengurai Nitrogen. Hal ini didasari oleh kandungan silica dan kalsium pada media tanam batu apung yakni masing masing sebesar 70 dan $25 \%$, kandungan sebesar itu cukup untuk syarat hidup bakteri pengurai Nitrogen yakni sebesar $20-78 \%$.

Kandungan oksida silika pada batu apung menjadi faktor utama penyerapan Posfat oleh tanaman. Lindsay (2009) menyatakan bahwa kandungan oksida silika pada batu apung akan memecah unsur posfat lengkap (PO4) menjadi unsur posfat tunggal (P). Yang dkk (2018) memperkuat pernyataan ini dalam penelitiannya yang mengatakan bahwa unsur tanaman hijau tanpa batang sempurna seperti bayam, sawi, kalian, pakcoy, dan seterusnya hanya menyerap Posfat tunggal.

\section{Kesimpulan}

Batu apung merupakan media tanam terbaik dibandingkan dengan akar pakis dan serabut kelapa. Batu apung menurunkan nitrat dan pospat sejumlah $65,55 \%$ dan $94,06 \%$. Penggunaan batu apung memberikan sintasan $69,3 \%$ dengan laju pertumbuhan spesifik sebesar $2,3 \%$ per hari..

\section{Daftar Pustaka}

Akihino, T. (2015).Reusing Fish Waste on Provoltaltik Water Pump For Thilapia and Carp in Hiroshima Prefacture Japan. Green Leave Journal vol 3(4): 10 - 13

Cohen, A.S. (2010). Gravel Structure for Aquaponics. FAO Papper Publisher Vol(2):19. Rome. 
Cohen, A., S. Malone, Z. Morris, M. Weissburg, B. Bras. (2018). Combined Fish and Lettuce Cultivation: An Aquaponics Life Cycle Assesment. Procedia CIRP Vol(69): 551 556.

Dauhan, R.S., E. Efendie, Suparmono. (2014). Efektifitas Sistem Akuaponik Dalam Mereduksi Amonium Dalam Budidaya Ikan. E-Jurnal Rekayasa Dan Teknologi Vol 3 (1) : $297-302$.

Dwiyanti, S.D., Dan B. Gunadi. (2006).Efektivitas Biofilter Tanaman Air Terhadap Pengolahan Limbah Udidaya Ikan Dengan Sistem Resirkulasi. Prosiding Seminar Nasional Limnologi Lipi. Jakarta, 11 September - 13 September 2006: 9-11

Kyaw, T.Y., Dan A.K. Ng (2017). Smart Aquaponics System for Urban Farming. Energy Procedia Vol (143) : 342 - 347.

Kementrian Lingkungan Hidup. (2010). Undang Undang No 3 Tahun 2010 Tentang Baku Mutu Air. KLHK-RI.Jakarta.

Lee, J.Y., A. Rahman, M.J. Kwon. (2018). Nutrient Removal From Hydroponic Wastewater By A Microbial Consortium and A Culture of Paracercomonas saepenatans. New Biotechnology Vol (41) : 15 - 24.

Lindsay, M.O. (2009). Chemistry on Structure Gravel by Using The Integrated Aquaculture Method. FAO Paper Publisher Vol(2):30. Rome

Napitupulu, R.J. (2011). Pengolahan Ikan Mas (Cyprinus Carpio L). Kementrian Kelautan dan Perikanan, Badan Pengembangan SDM Kelautan dan Perikanan Pusat Penyuluhan Kelautan dan Perikanan. Jakarta.

Pranawa, V.G. (2013). The Analitic Structure Of Gravel And Combination With Integration Between Fish Pond System And Plants. Delhi Fisheries Pers Vol 13 (3): 12-15.

Pujiastuti, S.R. (2014). Pengaruh Penggunaan Ragi Kapang Terhadap Pengurairan Bahan Organik Pada Kolam Ikan Lele (Skripsi Tidak Terpublikasi). Universitas Muhamadiah Malang. Malang.

Rifai, M., P.R. Ika. (2012). Pemanfaatan Photovoltaik Pada Sistem Otomasi Akuaponik Berbasis Mikrokontroler Atmega 8535.Jurnal ELTEK Vol 2 (2): 22-32.

Somerville,C., M. Cohen, P. Eduardo, S. Austin, A. Lovatelli. (2014). Small Scalle Aquaponic Food Production. FAO Fisheris And Aquaculture Publisher. Rome.

Sutrisno. (2007). Budidaya Ikan Air Tawar. Ganeca. Jakarta.

Wongkiew, S., Z. Hu, K. Chandran, J.W. Lee, S.K. Khanal. (2017). Nitrogen Transformations in Aquaponic Systems: A Review. Aquaculture Engineering Vol (76) : 9-19.
Yang P., Y. Guo., L. Qiu. (2018). Effects of Ozone Treated Domestic Sludge on Hydroponic Lettuce Growth and Nutrition. Journal of Integrative Agriculture Vol 17 (3): 593 - 602. 